\title{
In memory of Harry K Genant
}

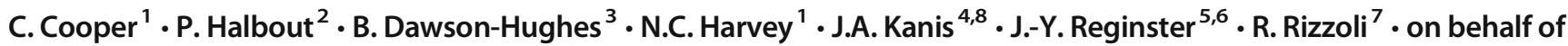 the International Osteoporosis Foundation}

Published online: 26 January 2021

(C) International Osteoporosis Foundation and National Osteoporosis Foundation 2021

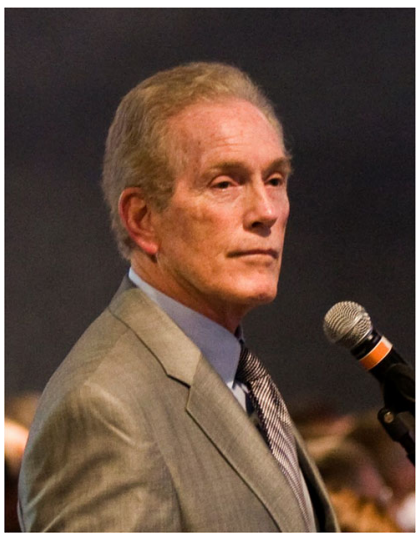

The International Osteoporosis Foundation (IOF) is deeply saddened to learn that Professor Harry K. Genant passed away on January 14, 2021, at the age of 78. With his passing, the bone field has lost not just a brilliant scientist but a much-loved friend, esteemed colleague, and important mentor to many in the bone community.

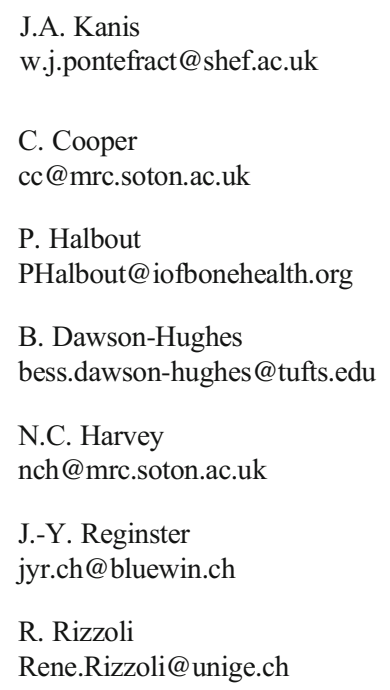

We extend our heartfelt condolences to his wife of 52 years Gail and to his three children and five grandchildren.

IOF was honoured to count Harry Genant as an elected member of its Board of Governance for over two decades: initially from 2004 to 2016 and subsequently for the 2020 2024 term. As an esteemed member of our Committee of Scientific Advisors, he served as the Co-Chair of the IOF Bone Imaging Working Group which concluded its work in 2012. As Co-Chair of the IOF Global Initiative on Vertebral Fracture Assessment and of the IOF Bone Quality Working Group, he was instrumental in the development of the Vertebral Fracture Risk Assessment Initiative, created to encourage radiologists to detect vertebral fractures on radiographs, to report them clearly as fractures, and to recommend appropriate investigation and treatment. In recognition of his outstanding scientific achievements, Professor Genant was awarded the prestigious IOF Olof Johnell Science Award in 2013 and the 2019 IOF Medal of Achievement.

Dr Genant's impressive biography (see below) reflects his many seminal academic and professional achievements. He is revered in the bone field for his inspiring and ground-breaking

1 MRC Lifecourse Epidemiology Unit, University of Southampton, Southampton, UK

2 NIHR Musculoskeletal Biomedical Research Unit, University of Oxford, Oxford, UK

3 Jean Mayer USDA Human Nutrition Research Center on Aging, Tufts University, Boston, MA, USA

4 Mary McKillop Institute for Health Research, Australian Catholic University, Melbourne, Australia

5 Biochemistry Dept., College of Science, King Saud University, Riyadh, Kingdom of Saudi Arabia

6 Department of Public Health, Epidemiology and Health Economics, University of Liège, Liège, Belgium

7 Service of Bone Diseases, Geneva University Hospitals and Faculty of Medicine, Geneva, Switzerland

8 Centre for Metabolic Bone Diseases, University of Sheffield Medical School, Sheffield, UK 
work in non-invasive and quantitative imaging methods for osteoporosis, inflammatory and osteoarthritis, and other musculoskeletal disorders. His simple spinal fracture assessment algorithm is arguably one of the most influential tools in advancing the diagnosis and treatment of vertebral fracture. Among his many accomplishments, Dr Genant was renowned as an educator and mentor, having been an influential mentor to many of the field's current national and international leaders.

We have lost a wonderful colleague and friend, a leading light in the bone field who leaves a great legacy of fielddefining research. Harry will be greatly missed and never forgotten.

\section{Professional career}

Harry K. Genant, MD, was Professor Emeritus at the University of California San Francisco and Chairman Emeritus of the Board of Directors of Synarc, Inc. He received his medical degree from Northwestern University in Chicago, IL, and completed his internship on the Osler Service at Johns Hopkins University in Baltimore, MD. He received residency training in Medicine and in Radiology at the University of Chicago and was Chief Resident and Assistant Professor in Radiology. In 1974 he joined the faculty of the University of California, San Francisco, as Chief of Musculoskeletal Radiology. He remained at UCSF for over 30 years, becoming Professor of Radiology, Medicine, Epidemiology and Orthopaedic Surgery. He founded the Osteoporosis and Arthritis Research Group (OARG) in the Department of Radiology, UCSF, and served as its Executive Director. This group, once numbering over 130 physicians, scientists and research associates, was recognized as a leading source of research on the development and assessment of non-invasive and quantitative imaging methods for osteoporosis, arthritis and orthopaedics. In 1998 he co-founded Synarc, Inc., a global, contract research organization (CRO) specializing in management of quantitative imaging and biomarkers in large, multicentre, multinational, pharmaceutical drug trials. He served as a Member of the Board of Directors from 1998 to 2013, and later as a Senior Consultant for Synarc/BioClinica.

During his long and productive academic career, Harry Genant was editor or co-editor of more than 40 books and authored more than 300 chapters and invited reviews, as well as over 600 original research articles in peer-reviewed scientific and medical journals. He was a much sought-after speaker at national and international scientific and professional gatherings. He was past Associate Editor of Bone, Associate Editor of Journal of Orthopaedic Translation and Editorial Board Member of Osteoporosis International and the Journal of Clinical Densitometry.

Among the numerous awards and honours that Harry received were honorary lifetime memberships of the American Academy of Orthopaedic Surgeons and the International Society for the Study of the Lumbar Spine. He was an honorary member of the Italian Radiolologic Society, the Chinese Osteoporosis Society, the Chilean Society of Osteology, the Hungarian Society of Osteology and the European Society of Skeletal Radiology. He was a Fellow of the American College of Radiology and an Honorary Fellow of the Royal College of Radiologists, UK. He was named The Outstanding Physician of the Year in 1998 and the recipient of The Paul D. Miller ISCD Service Award in 2013, by the International Society for Clinical Densitometry. He was designated The Annual Orator in 2004, by the Radiologic Society of North America, and The Louis Avioli Annual Lecturer in 2012, by the American Society of Bone and Mineral Research. He was elected by the American College of Rheumatology as an ACR Master in 2012 and was named the IOF Olof Johnell Science Awardee in 2013 and recipient of the IOF Medal of Achievement in 2019.

In addition to his positions within IOF, Dr. Genant served as President of the Association of University Radiologists, President of the International Skeletal Society, First President and Founder of the International Bone Density Workshop series, Scientific Chair of the First through Sixth International Congresses on Osteoporosis in China, Co-Chair of the Second International Conference on Osteoporosis in Japan, Chair of the WHO Task Force on Osteoporosis, Chair of the International Steering Committee for Artificial Gravity for the joint US, German and Russia Space Programs and Member of the Radiologic Devices Panel of the US Food and Drug Agency.

Publisher's note Springer Nature remains neutral with regard to jurisdictional claims in published maps and institutional affiliations. 